\title{
Reflexões sobre a Filosofia como componente curricular da Educação Básica
}

\section{Reflections on philosophy as a curricular component of Basic Education}

\author{
Maria Clara Pereira Santos \\ Doutoranda na Universidade Federal do Rio Grande do Norte, Natal, Rio Grande do Norte, Brasil \\ clara_ygraine@hotmail.com
}

Recebido em 06 de junho de 2018

Aprovado em 12 de novembro de 2018

Publicado em 23 de janeiro de 2019

RESUMO: Este artigo se propõe refletir sobre a filosofia na educação escolar. Sua metodologia se baseia na Teoria Crítica de Theodor Adorno e M. Horkheimer, que é usada na construção de uma tecedura expositiva em que os endereços históricos do ensino da filosofia são trazidos como pontos de apoio para fazer emergir as fissuras de contradição envolvendo a relação entre o conhecimento da filosofia e o espaço dado à mesma na educação formal brasileira. Nosso objetivo é problematizar o horizonte desse ensino de filosofia fazendo uso de sua historicidade no exercício do pensar elucidativo. Por isso, os pontos de contradição trazidos pela análise histórica endereçadora da relação tempo-espaço e da modelação dos elementos identificativos do ensino da filosofia nos servem como fios condutores que tornam razoável a visibilização desse horizonte em suas lacunas potenciais. A conclusão desse artigo, coerente com seu ponto de apoio metodológico, não preconiza uma fórmula de salvação, pelo contrário, ela pressupõe tornar audível uma voz encarnada de várias vozes sobre o tema do ensino da filosofia como componente curricular, acreditando que o diálogo aberto já faz parte do próprio exercício filosófico de pensar a si mesmo como conteúdo escolar necessário para um projeto coletivo de sociedade democrática. Palavras-chave: Educação; Ensino da Filosofia; Teoria Crítica.

\begin{abstract}
This paper proposes an analysis about philosophy in school education. Its methodology is based on the Critical Theory proposed by Theodor Adorno and Max Horkheimer, which is used in the construction of an expository web where the historical addresses of the philosophy teaching are brought as supporting points to create the fissures of contradiction involving the relation between the knowledge of philosophy and the role given to it in Brazilian formal education. Our goal is to problematize the horizon of such philosophy teaching using its historicity in the exercise of the elucidative thinking. That is why the contradiction points brought by the historical analysis addressing the time-space relation and the modelling of the identifying elements of the teaching of philosophy serve as conducting threads that make it reasonable to see this horizon in its potential gaps. The conclusion of this article, consistent with its methodological approach, does not advocate a formula of salvation, quite the opposite, it presupposes to make audible a voice incarnated of several voices on the subject of teaching philosophy as a curricular component, believing that open dialogue is already part of the philosophical exercise of thinking about itself as school content necessary for a collective project of democratic society. Keywords: Education, Philosophy teaching; Critical Theory.
\end{abstract}




\section{Introdução}

Para se dar início ao exercício do pensar filosófico, que esse artigo se propõe ser, tendo como base central de sua construção o refletir sobre a Filosofia como componente curricular da Educação Básica, é importante que, antes de mais nada, apresentemos seu instrumento metodológico, isto é, as lentes que foram usadas para tornar visíveis os ângulos de onde se analisou o objeto de estudo. Logo, se torna premente expor de forma didática o que pressupõe o uso da teoria crítica como caminho de construção teórica material.

A teoria crítica como caminho do construir teorias materiais deve partir da visibilização das conjunturas particularizantes que permeiam a formação da identidade definidora do objeto, pois, mais do que entender que a "Teoria é o saber acumulado de tal forma que permita ser este utilizado na caracterização dos fatos tão minuciosamente quanto possível"1, a teoria deve proporcionar a consciência da imersão do sujeito construtor de identidade no seu meio historicizador. Logo, falamos de uma teoria denunciadora de teorias que ignoram os filamentos que formam os lugares de imersão (ADORNO, 2009). Assim, observamos que essa nos serve como um metainstrumento que parte do horizonte imersor do professor de filosofia para, por meio do exercício crítico emersor, trazer à tona o próprio silenciamento dos lugares de imersão de onde se dá a prática desse professor.

Desse modo, ao iniciarmos a caminhada sobre solo teórico crítico, devemos tornar visível o entrelaçamento entre o passado, o presente e o futuro, localizando os meios de mediação entre o humano e o real instituído, construindo uma imagem "desenvolvida do todo, do juízo existencial englobado na história". ${ }^{2}$ É inerente, nesse processo de busca dos filamentos tecedores do objeto, em relação com seu meio imersor espacial-temporal, expor as contradições constituídas por essa própria relação imersora. Pensemos, aqui, a tecedura complexa que forma a identidade dos nossos lugares profissionais, que forma nossos horizontes como educadores de um conhecimento com uma identidade, categorizada nos documentos, nos textos que nos servem como pontos de orientação etc. Assim, tais contradições nos serviriam como espaços de criação do novo possível, pois elas seriam, como esclarece Adorno (2009), aquilo que extrapola o princípio de identidade: o não-conceito, a não-identidade são os elementos que escapam à dominação do pensar do sujeito e denunciam o próprio processo de dominação. Transferindo essas ideias para a especificidade desse artigo, pensemos que a visibilização das contradições formativas do nosso horizonte de formação como professores nos geram espaço de criação de novos modos de ser professores, novos modos de criar práticas enquanto tais.

Usar a teoria crítica como processo visualizador dos problemas do ensino da filosofia leva-nos, como professor de filosofia, a buscar nas contradições da história do ensino da filosofia o entendimento da tensão entre o possível idealizado e o concretizado. Nesse processo, o sentido potencial do ensino da filosofia é levado a se chocar contra o sentido concretizado instituído. O empasse entre as potencialidades, o endereçamento histórico e o lugar atual do ensino da filosofia no Brasil aparecem como denunciadores daquilo que foi arrastado para as bordas do ensino da filosofia instituído pela razão instrumental. 


\section{Compreendendo as potencialidades do ensino da Filosofia}

Adorno, em sua obra "Dialética Negativa", critica a filosofia que se deixou povoar pelo princípio de dominação que reduz a experiência do pensar livre a um mero construir conceitual sistemático e generalizador. As potencialidades filosóficas, que seriam a experiência do pensar sem amarras, tornam-se reprodutoras dos filamentos imersores que assimilam tudo que é dissonante à realidade estática, onde o indivíduo se move por um extinto de sobrevivência orientador de todo o seu ser.

O mundo amarrado objetivamente em suas bordas e transformado em uma totalidade não deixa a consciência livre. Ele a fixa incessantemente no pondo de onde ela quer se evadir. [...] O poder do existente erige as fachadas contra as quais se debate a consciência. Essa deve ousar atravessá-las. [...] Lá onde o pensamento se projeta para além daquilo a que, resistindo, ele está ligado, acha-se a sua liberdade. Essa segue o ímpeto expressivo do sujeito. A necessidade de dar voz ao sofrimento é condição de toda verdade. Pois sofrimento é objetividade que pesa sobre o sujeito: aquilo que ele experimenta como seu elemento mais subjetivo, sua expressão, é objetivamente mediado. ${ }^{3}$

Notemos que, dentro dessas determinações de materialidade do sentido do filosofar, cabe à filosofia denunciar a si mesma como reprodutora desse ver-mundo fechado em si, tal que ela, em seu movimento paradoxal, ao buscar espaço de desenvolvimento reflexivo, gera tensões entre a reflexão filosófica e as amarras que docilizam. Imaginemos, a título de exemplo, na situação de um professor de filosofia que ministra uma aula sobre "o que é filosofia". Coerente com o sentido adorniano, ele teria que usar da história da filosofia ou do exercício de filosofar para expor as contradições da própria filosofia, as dores que carrega e, nesse processo, expor a mobilidade da história da filosofia como característica do ato de filosofar. Contudo, esse professor, sendo levado por aquilo que sustenta sua identidade como tal, pode se deixar prender por um sentido prefixado que lhe pareça mais seguro abordar e, pelo instinto sistematizador, nega ousar e deixa de expor a mobilidade da filosofia.

As formas de pensamento querem ir além daquilo que está meramente presente, daquilo que é dado. A ponta aguda que o pensamento dirige contra o seu material não é apenas a dominação espiritualizada da natureza. Violentando aquilo sobre o que exerce suas sínteses, o pensamento segue ao mesmo tempo um potencial que aguarda naquilo que está à sua frente e obedece inconscientemente à ideia de ressarcir os fragmentos pelo que ele mesmo perpetrou; para a filosofia, esse elemento não-consciente tornar-se consciente. O pensamento irreconciliável é acompanhado pela esperança de reconciliação porque a resistência do pensamento ao meramente ente, a liberdade imperiosa do sujeito, também procura obter do objeto aquilo que se perdeu por meio da sua transformação em objeto. ${ }^{4}$

Explica-se, desse modo, por que, historicamente, tanto a filosofia se tornou a exposição do poder do homem fazendo uso do seu pensar, como foi demonizada como 
instrumento de subversão quando extrapolava o produzir dentro do aceitável como produtivo. Esses apontamentos de Adorno (2009) sobre a filosofia são consonantes com aquilo que o pesquisador brasileiro Walter Omar Kohan (2003) afirma em relação a ela. Ele afirma que a filosofia tem duas dimensões: a formativa, vinculada aos preceitos modeladores do ato de filosofar, e a não formativa, que seria a resistência do ato de filosofar aos preceitos deterministas do exercício do pensar. O sentido conceitual de formação e de não formação de Kohan (2003) inverte o sentido comum desses termos ao colocar no conceito de "não formativo" o poder da filosofia e, por sua vez, no conceito de "formação" aquilo que tende enformar a potencialidade filosófica a qualquer coisa, menos à sua própria potencialidade. Por sua vez, o ensino da filosofia como componente curricular carregaria consigo tal paradoxo, fruto do processo de docilização da filosofia em seu potencial de resistência.

Se usamos essa afirmação no sentido adorniano entendemos que o âmbito não formativo do ensino da filosofia seria a exposição daquilo que escapa ao processo de passivação do pensamento filosófico, não deixando de fazer parte do momento formativo desse ensino, a não ser se falamos do sentido compatível com a heteronomia instrumental. Entenderemos, assim, a afirmativa de Antônio Joaquim Severino (2003) ao inferir que o ensino da filosofia tem, por trás de si, tanto elementos vinculados ao próprio sentido da aprendizagem, como vinculados a sentidos políticos.

É importante esclarecermos que Severino (2003) colocará esse sentido político como produto das relações humanas que concretizam o que coletivamente é aceito e intersubjetivizado como sentido do ensino de filosofia, por sua vez, o âmbito da aprendizagem estaria vinculado ao movimento individual de criar significações identificativas. Logo, notemos que há uma mediação entre o sentido formativo do ensino da filosofia vinculado às relações sociais e a relação do ser consigo mesmo.

\footnotetext{
O indivíduo que faz essa descoberta pode agregar ao seu caráter um desses dois importantes elementos: a resistência ou a submissão. $O$ individuo que resiste irá opor-se a qualquer tentativa pragmática de reconciliar as demandas da verdade e as irracionalidades do existente docilizado. Em vez de sacrificar a verdade conformando-se aos padrões dominantes, ele insistirá em expressar em sua vida tanta verdade quanto possível, tanto na teoria quanto na pratica. ${ }^{5}$
}

Notemos que a mediação entre o sentido formativo político e de aprendizagem expõe uma abertura de onde se pode escapar o não-heteronômico filosófico, ao tornar o produto da filosofia um processo filosófico e expor para o professor-filósofo que mesmo a identidade epistêmica da filosofia e o formato do seu ensino se fazem dentro de um confronto entre os elementos formativos reprodutores do princípio de dominação do humano instituído por uma vivência dominadora provinda da dor do se sentir coletivamente sobre o jugo de uma natureza desumana. O que desvelamos, aqui, é a subjetividade significante da construção da identidade do professor-filósofo, que tanto vai estar forjado pelas potencialidades do filosofar incomensurável, como essa própria ação imprevisível se dará em um campo de sentido social-histórico, em que é encarnado no fazer do sujeito 
o seu endereçamento histórico. Assim, é plausível entender que essa caracterização identificativa será carregada dos traços determinantes espaciais-temporais, uma vez que

Falar da prática e do ensino da filosofia nos remete ao exercício da subjetividade - o que nos faz lembrar que toda atividade intelectual humana, todo conhecimento como expressão dessa subjetividade, já emerge no plano histórico e antropológico da espécie, intimamente articulado com o todo da prática existencial do homem. O conhecimento surge como estratégia da existência. ${ }^{6}$

Para exemplificarmos o que foi falado até esse ponto, usemos o método da dialética negativa de Adorno (2009) para trazer à tona a constelação de sentidos do conceito de formação envolvendo o ensino de filosofia. Pensemos que fazendo parte dessa constelação temos a conceituação de formação de Severino (2003), que nos apresenta dois sentidos formativos vinculados a expectativas do ensino do conhecimento filosófico. Por outro lado, o conceito de formação e não formação de Kohan (2003) representa, nessa constelação de sentidos, a mobilidade no conceito de formação e, por isso, faz uso do não-idêntico conceitual, o não-conceito, nesse caso, o conceito de não-formação e formação de Kohan (2003) como motor extrapolado que problematiza os sentidos que formam essa constelação de sentidos conceituais e vão se tornando elementos empobrecedores do conceito de formação. Por fim, devemos notar que a não formação de Kohan é coerente com o sentido de formação de Severino (2003), uma vez que esses dos conceitos se encontram nos sentidos críticos que os montam. Entretanto, no caso de Kohan (2003), seu objetivo é denunciar o lado negativo do conceito de formação do ensino de filosofia que termina por não ser filosófico, e, por isso, o uso do sentido negativo. Já no caso de Severino, o objetivo é evidenciar a mobilidade do próprio conceito de formação mostrando duas faces que remetem a um outro horizonte conceitual, que é o político e o da aprendizagem. Observemos que é importante que tenhamos esse movimento epistêmico adorniano em mente para lidar com a tecedura complexa que institui a identidade formativa do ensino de filosofia.

Pensar o sentido de formação trazido pelo ensino de filosofia nos leva a lidar com uma identidade de formação espiralada que, a cada volta que dá, ao mesmo tempo que se expande, saindo do lugar anterior, aproxima-se dos pontos indicadores do seu lugar de fuga do próprio ponto de origem formando um horizonte, uma constelação de sentidos e de outros conceitos e seus não-conceitos, que nos montam o mover do conceito de formação identificativo do ensino de filosofia. Desse modo, a cada reviver da discussão do ensino da filosofia revive-se sua identidade, revolvendo as amarrações que amordaçam as potencialidades não formativas desse ensino, tal que, ao tornar o produto filosófico um processo, abre-se o espaço do deslocamento da identidade formativa do professor-filósofo que se faz em sua práxis.

Nesse sentido, a cada momento histórico trazido pela problematização do processo filosófico abre-se uma nova oportunidade de conquista de espaços de respiração no âmbito não formativo no sentido heteronômico, que pode ou não ser assimilado, a depender das contradições que sejam rompidas ou reproduzidas pela práxis da ação social do professor-filósofo e do aluno-iniciado. 


\section{A historicidade do ensino da Filosofia e sua denuncia}

Pesquisadores como Silvio Gallo, Walter O. Kohan, Antonio J. Severino e Geraldo B. Horn, ao abordarem o ensino da filosofia problematizando sua história dentro do espaço de ensino formal no Brasil, atentam para o lugar elitista que esse ensino foi colocado, mesmo esses autores compartilhando o preceito de que o ensino da filosofia teria uma potencialidade libertadora, dada sua relação com o exercício do pensar livre. Tais pesquisadores do tema denunciam que, historicamente, quando o ensino da filosofia é colocado como componente curricular dentro dos espaços de ensino formais, acaba sendo vinculado a um espírito propedêutico que valoriza os conteúdos deterministas da filosofia, como por exemplo: a relação do ensino da filosofia com a política teológica jesuítica que, ao oferecer instrução por meio do curso de filosofia, buscava não o exercício livre do pensar, mas a construção de um exército de Deus que combatesse as ideias contrárias à igreja católica. "Tratava-se de uma filosofia decorrente do monopólio do pensamento teocrático-jesuítico" que, na prática, servia de instrumento semiformativo (ADORNO, 1992).

As demais etapas da relação do ensino da filosofia e de seu lugar materializador dos traços do seu endereço de imersão social-histórica concordam com a afirmativa de que o ensino da filosofia serviu como um instrumento de semiformação ${ }^{8}$, tal que, para cada momento histórico em que as singularidades do princípio de dominação tomavam tonalidades diferentes, valorizavam-se elementos consonantes às necessidades das conjunturas de coisificação do indivíduo desumanizado em sua singularidade histórica. Assim, se no período colonial os jesuítas ensinavam filosofia por meio do radio studiorum tomista ${ }^{9}$, com o advento do iluminismo no Brasil o ensino da filosofia reflete o poder das ideologias racionalistas cientificistas com seu ímpeto enciclopédico e sua sistematização prolixa. Por sua vez, com as necessidades da realidade das tecnologias da industrialização, o pragmatismo lógico torna-se centro epistêmico desse ensino que caminha sobre o jugo do cientificismo minimalista totalizante.

O ensino da filosofia no nível médio, assim como as demais disciplinas, tem se limitado a repassar e reproduzir conhecimentos estáticos e acabados, bem como concepções e verdades absolutas que inviabilizam o processo de ação e reflexão do homem sobre o mundo e sobre sua própria existência. É nesse repasse mecânico de teorias desarticuladas da realidade que reside, em boa parte, a problemática do ensino de filosofia. ${ }^{10}$

É no movimento de mecanização da educação formal, tornada aparelho de dominação do humano coisificado, que o ensino da filosofia se desencaixa de si mesmo, de sua característica como exercício profundo do pensar livre, tornando-se puro produto de um processo que vem de fora. Pois, nas conjunturas da dominação como meio organizador, o ensino da filosofia está sempre cheio de determinações, não deixando espaço para a criação do aprofundamento do sujeito auto reflexivo que usa seu poder de se desnudar para vivenciar o aprofundamento da sua experiência como existente, a criação do processo como produto vivificado. "Quando se ensina filosofia para afirmar [...] ordens determinantes [...], se impossibilita a filosofia"11, pois, explica 
Kohan, os determinantes do exercício do pensar filosófico não podem ser pontos de chegada pré-estipulados, mas problemas a serem revolvidos pelo exercício do pensar movente. Para exemplificar, pensemos os vários momentos em que um professor de filosofia se depara com os sentidos contraditórios que formam o que é esperado de suas aulas e notemos que, muitas vezes, esse professor deixa de lado o seu exercício de encontro como professor coerente com a atividade filosófica quando internaliza essas contradições e as toma como pontos de apoio legitimizadores de suas práticas, terminando por se distanciar da própria filosofia.

Desse modo, o que observamos na história do ensino da filosofia no Brasil é o contínuo constrangimento que a filosofia passa ao se colocar no espaço instituído pelo princípio de dominação alienante que, em nossas conjunturas, sempre esteve atrelado ao processo de dominação da maioria por uma minoria. Assim, é plausível entender que, mesmo o ensino da filosofia tendo sido pendular dentro dos espaços públicos de ensino, como afirma Horn (2000), ela sempre esteve presente nos currículos das melhores escolas particulares de lugares como São Paulo, como afirma a pesquisadora Lídia Maria Rodrigo (2009), ou mesmo nunca perdeu seu espaço livresco nas universidades. Nesses espaços, o conhecimento filosófico geralmente serve como instrumento de diferenciação daqueles que têm o poder de acesso e daqueles que não têm. Isso fica claro quando nos deparamos, nessas conjunturas de dominação, com discursos que naturalizam a filosofia como meio do pensar de poucos, como lugar da reflexão que exclui os não dotados dos meios de acesso a esse conhecimento (CABRERA, 2010). Dentro desses lugares de adaptação do que se deve ensinar por filosofia, acontecerá sempre um recorte identificativo que, conforme a necessidade dos meios de opressão, delimita os conteúdos a serem transferidos por aqueles que devem ser capacitados dentro desse sentido de utilidade dominante.

\footnotetext{
No atual panorama [...] o problema inicial não é a dificuldade em saber o que seja Filosofia, mas, pelo contrário, o problema de sabermos perfeitamente o que ela seja. De acordo com os padrões monotonamente recitados pela comunidade de filósofos. Filosofia é atividade de reflexão teórica, com vocação universal, que opera com métodos argumentativos em contato com a tradição filosófica ocidental. [...] $\mathrm{O}$ problema não é, pois, o de não sabermos o que seja Filosofia, mas de sabe-lo demasiado. ${ }^{12}$
}

Essa contradição se expõe na construção de uma identidade determinada que serve, atualmente, ao processo de profissionalização pela capacitação do indivíduo empreendedor e flexível, capaz de se adaptar às mudanças do mundo moderno. Mais uma vez, a história torna possível a visibilidade da dor da dominação, tal que, se no primeiro momento da modernidade o ensino da filosofia era atrelado a elementos determinantes que a afastavam do seu sentido produto-processo filosófico, agora, com as necessidades de adaptação à flexibilização dos meios de produção neoliberal, o caráter de refletividade do exercício do pensar é assimilado e atrelado a uma necessidade do indivíduo empreender, que precisa se tornar dinâmico, ágil, capaz de lidar com os meios de comunicação icônicos que lhe impõem capacidade representativa. 
Nessas novas conjunturas, em que a dialética se dá no conflito instituinte e no momento de materialização do instituído pelo processo coletivo de instituir as necessidade sociais, as normatizações que norteiam as competências e habilidades a serem desenvolvidas em filosofia expõem os lugares-comuns reproduzidos, como: a dicotomização entre o filosofar e a filosofia; a redução da filosofia a um saber que oferece uma síntese totalizante dos conhecimentos preestabelecidos; a naturalização da filosofia como instrumento opressivo; o esvaziamento da filosofia de sentidos concretos-práticos (GALLO, 2000).

Mesmo documentos como os Parâmetros Curriculares Nacionais (BRASIL, 2000) e as Orientações Educacionais Complementares (BRASIL, 2006), sendo exposiçoes de lutas políticas que materializam a dialética envolvendo os lugares de fala daqueles que fazem parte da construção de tais docuementos, não fogem do sentido docilizador do seu contexto macro em relação ao seu contexto micro, pois, as próprias falas libertárias que protegem o lugar da filosofia no ensino formal e materializam os lugares de fuga trazem consigo as marcas da negação que as particularidades sofrem quando a heteronomia prevalece. Por isso mesmo, para Adorno (2012), em seu livro póstumo, Educação e emancipação, há crivos de enformamento que vão docilizando o estudante de filosofia em seu processo de profissionalização, o adequando ao que já está instituído como determinante, tirando as possibilidades da construção de um professor-filósofo. Nesse sentido os vários pontos determinantes que desestimulam nossa maturação como professores de filosofia, por prefixarem normatizações engessadoras dos nossos exercícios de descobertas como docente de filosofia, se desdobram como empobrecedores de nossas atividades docentes.

\section{Os espaços de deslocamento dos sentidos opressivos do ensino da Filosofia}

O olhar dialético, que nos leva a lidar com o não-idêntico sobre o identificado, nos possibilita vivenciarmos o constrangimento existencial de sair do centro pelo exercício do autorefletir (ADORNO, 2009). Esse movimento de aprofundar-se em si mesmo, sem ignorar o entorno, enlarguesse a consciência experienciadora do existir por lhe proporcionar a vivência da profundidade da sua criação. Nessa perspectiva, os elementos identificativos, como por exemplo os conceitos, as categorias, são vistos como momentos de aproximação, não de dominação. Para Horkheimer (2015), aquele que transcendeu ao conflito é capaz de resistir ao impulso instituído de dominar para se proteger. A real razão de sua atitude é sua compreensão de que a realidade - como lhe é imposta - é falsa. Logo, é por meio dos exercícios reflexivos que o indivíduo é capaz de resistir ao seu endereçamento de dominação. No caso do professor de filosofia, é importante que ele não se deixe acomodar às normatizações e se mantenha um degustador de si e do seu universo como professor, ousando, criando, descobrindo como ser um formador a partirdo universo do seu espaço escolar, pois, para a filosofia, não se trata de um saber mais, de uma quantificação informativa, mas "um ser mais mediante uma indagação sobre o mundo" ${ }^{13}$.

"Quanto menos é possível afirmar a identidade entre sujeito e objeto, tanto mais contraditório se torna aquilo que é atribuído ao sujeito como cognoscente, uma força desatrelada 
e uma autorreflexão aberta". ${ }^{14}$ Essa problematização, se trazida para a realidade do ensino de filosofia, estaria nos dizendo o quanto é importante sair dos lugares de conforto pré-formativos e experienciar a construção do seu lugar como professor-filósofo, fazendo uso do universo escolar para ousar ser filosófico, trazendo a multiplicidade da realidade à nossa volta para construirmos nossas práticas formativas filosóficas. A pluralidade da realidade dos seus alunos, de suas aulas, de seu contexto, a ser degustada pelo professor de filosofia, deve ser o lugar de resistência que o faz se deslocar do sentido de formação semiformador, logo, não filosófico, e o empurra para suas próprias descobertas como professor, tal que

[...] a consciência de que, neste exato momento, tudo depende do uso correto da autonomia do homem deveria unir aqueles que não foram silenciados, a fim de defender a cultura contra a ameaça de sua degradação nas mãos de seus falsos amigos conformistas ou contra sua aniquilação nas mãos dos bárbaros entre muros. ${ }^{15}$

Ao professor de filosofia cabe, então, entender seu lugar de imersão em sua complexidade e fazer uso das contradições desse lugar como espaço de resistência, ousando filosofar sobre o universo no qual ele ensina. Ao aluno de filosofia cabe construir espaços vazios onde os professores de filosofia possam auxiliá-lo no experimento da ousadia. Contudo, não se pode esquecer que "Não há fórmula, a descrição adequada, desdobrando o sentido de qualquer um dos conceitos, com todas as suas sombras e interconexões com outros conceitos, é ainda a principal tarefa". ${ }^{16}$ Aqui, a identidade "[...]com suas camadas semiesquecidas de sentido e de associação, é o principio orientador. Essas implicaçoes têm de ser re-experienciadas e preservadas, por assim dizer, em ideias mais esclarecidas e universas". ${ }^{17}$ Logo, é necessário que o professor localize o que o impede de ser um desdobridor como professor de filsofia e entenda como esses medos estão vinculados às contradiçoes do seu universo formativo, usando essa comprensão para se libertar do lugar comum como educador.

Usando Adorno (2002) e Horkheimer (1983), devemos entender que os elementos que formam nossa identidade, a história que constrói nossa formação, que molda onde estamos situados, deve ser revolvida e seus escombros usados para a construção do novo, de novas formas de entender a filosofia, de entender o ensino, de entender nossos alunos, de entender como e porque ser professor. "A elaboração do passado como esclarecimento é essencialmente"18 para a construção do novo. Por isso, para esse eu reflexivo, os endereçamentos identificativos que se dão nas teceduras espacias e temporais são instrumentos essenciais da problematização do conhecimento, que se propõe a não outorgar a realidade já dada, mas procurar fendas de realização do novo.

\section{Considerações finais}

A nosso ver, é o traço disforme da produção filosófica, em que tanto se faz a reprodução do instituído já dado, como a experiência do livre pensar, que promove a conscientização do próprio fenômeno da reprodução. Em contrapartida, atualmente, é esse traço que relaciona o 
ensino da filsofia às necessidades dos meios produtivos neoliberais, fazendo com que esse ensino se torne pensado como componente capacitador útil para as necessidades neoliberais. Desse modo, seria a disformidade, nesse contexto neoliberal, que, para Rodrigo (2009), impõe a aceitação da filosofia nos espaços educativos de países como o nosso, tal que seu ensino capacitaria os indivíduos a lidar com o dinamismo dos meios de produção atuais. Para isso, a filosofia passaria por uma assepsia minimalista que visa supervalorizar os aspectos consonantes às necessidades das conjunturas atuais, ao mesmo tempo em que são desqualificados os elementos que seriam dissonantes aos princípios norteadores dessa aceitação de inserção.

Contudo, o minimalismo hegemonizador não consegue lidar completamente com os espaços de abertura que a potencialidade do ensino da filosofia traz, uma vez que o exercício do pensar livre, que caracteriza a filosofia, remonta a um movimento de aprofundamento sobre si mesmo sem ignorar as amarras que Ihe sustentam. Assim, as identidades determinadoras que acompanham os sujeitos do exercício do pensar livre são levadas a se constrangerem com a visibilização compreensiva de si como reprodutor. Esse é o choque que a experienciação da reflexão filosófica em sua pluralidade nos oferece, por isso que não é abarcada pela totalização da razão instrumental.

A resistência do pensar livre nesse processo de constrangimento é a materialização dos furos no projeto moderno de dominação pela identidade pura e, por isso, é só em seus furos que o diferente torna-se possível. A resistência, assim, seria o lugar caracterizador do movimento do pensar-livre filosófico, pois que se dá em um vazio do determinado, deslocando os sentidos sólidos, produzindo espaço para o insólido inquisitor.

No ensino da filosofia, essa resistência significa resistência dos sujeitos em formação, deslocamento dos sentidos adaptativos enformadores. Por isso, esse ensino não tem uma fórmula preestabelecida que assegure a constuição desses lugares de furo. $O$ que podemos indicar como pontos norteadores são princípios qualitativos vinculados a uma ação didática-filosófica que impõe um se relacionar com a vida em seu estado de existente, incomodando-se diante dos elementos identificativos que entulham os lugares de vida e que, no ato do próprio viver em estado de experienciação profunda, se mostram em suas inexistências concretas.

Nessa direção da conquista desses lugares do exercício do pensar é crucial que o professor de filosofia se experimente em sua soltura existencial produtora de vivências profundas, como também é essencial que o aluno se mantenha aberto para o exericio do pensar. Por sua vez, é indispensável que nesse movimento de aprofundamento autoreflexivo, em coletividade, a temporalidade e a espacialidade sejam trazidas como meios orientadores do processo de problematização e deslocadoras de sentido.

A orientação da problematização não-formativa, mas proporcionadora da experiência do livre pensar, se compromete com a história, com o lugar onde se faz o tempo e o espaço em sua materialidade relacional constitutiva, por ser nessa história que as contradições se desdobram em determinações fantasiosas. Logo, acredita-se que é na vivência da tecedura do instituir nas especificidades do tempo-lugar que há uma experimentação de um todo aberto: o pensar busca a visibilização do que não está ali, levando a uma tensão entre o vivente humano e os elementos deterministas do espaço da vivência, ao ponto de produzir fissuras nas estruturas dos sentidos mantenedores das estruturas de heteronomização. Ao se olhar pelas bordas do 
que a identidade consegue abarcar, enrigessidas em seu caráter de segurança opressiva, o sujeito produtor dos processos de reflexão e deslocamento se depara com o vazio da identidade determinante que na solidez da identidade é negado como existente, mas nas bordas onde a identidade se encontra com a não-identidade torna possível a vivência da soltura.

\section{Referências}

ADORNO, Theodor W. Minima Moralia. São Paulo: Ática, 1992.

ADORNO, Theodor W. Dialética Negativa. Rio de Janeiro: Jorge Zahar, 2009.

ADORNO, Theodor W. Educação e Emancipação. São Paulo: Paz e Terra, 2012.

BRASIL, MEC/SEB. Parâmetros curriculares nacionais - Parte IV - Ciências Humanas e suas Tecnologias, Ensino Médio. Brasília: MEC/SEB, 2000.

BRASIL, MEC/SEB. Orientações Educacionais Complementares aos Parâmetros curriculares nacionais - Ciências Humanas e suas Tecnologias. Brasília: MEC/SEB, 2006.

CABRERA, Julio. Diário de um Filósofo no Brasil. ljuí: Unijuí, 2010.

GALO, Sílvio, KOHAN, Walter Omar . Crítica de Alguns Lugares-Comuns ao se Pensar a Filosofia no Ensino Médio. In GALO, Sílvio, KOHAN, Walter Omar (Org). Filosofia no Ensino Médio. Petrópolis, RJ: Vozes, 2000, p. 174-205.

HORN, Geraldo B. Apresença da Filosofia no Curriculo do Ensino Médio Brasileiro: uma Pespectiva Hiatórica. In GALO, Sílvio, KOHAN, Walter Omar(Org). Filosofia no Ensino Médio. Petrópolis, RJ: Vozes, 2000, p. 17-33.

HORKHEIMER, Max. Eclipse da Razão. São Paulo: Unesp, 2015.

HORKHEIMER, Max. Filosofia e a Teoria Crítica. In. BENJAMIN, walter. HORKHEIMER, Max. ADORNO, Theodor W. HABERMAS, Jurgen. Textos Escolhidos. São Paulo: Abril Cultural, 1983, p. 155-161.

HORKHEIMER, Max. Teoria Tradicional e Teoria Crítica. In. BENJAMIN, walter.

HORKHEIMER, Max. ADORNO, Theodor W. HABERMAS, Jurgen. Textos Escolhidos. São Paulo: Abril Cultural, 1983, p. 117-154.

KOHAN, Walter Omar. O Ensino da Filosofia Frente à Educação como Formação. In GALO, Sílvio. CORNELLI, Gabriele, DANELON, Marcio (org). Filosofia do Ensino de Filosofia. Petrópolis, RJ: Vozes, 2003, p. 33-49.

RODRIGO, Lidia M. Filosofia em sala de Aula: teoria e prática para o ensino médio. Campinas, SP: Autores Associados, 2009.

SEVERINO, Antônio J. O Ensino da Filosofia: Historicidade do Conhecimento e Construção da Aprendizagem. In GALO, Sílvio. CORNELLI, Gabriele, DANELON, Marcio (org). Filosofia do Ensino de Filosofia. Petrópolis, RJ: Vozes, 2003, p. 50-59. 


\section{Notas}

${ }^{1}$ HORKHEIMER, Max. Filosofia e a Teoria Crítica. São Paulo: Abril Cultural, 1983, p. 117.

2 HORKHEIMER, Max. Filosofia e a Teoria Crítica. São Paulo: Abril Cultural, 1983, p. 152.

${ }^{3}$ ADORNO, Theodor. Dialética Negativa. Rio de Janeiro: Jorge Zahar, 2009, p. 24.

${ }^{4}$ ADORNO, Theodor. Dialética Negativa. Rio de Janeiro: Jorge Zahar, 2009, p. 25.

${ }^{5}$ HOKHEIMER, Max. Eclipse da Razão. São Paulo: Unesp, 2015, p. 126.

${ }^{6}$ SEVERINO, Antônio J. O Ensino da Filosofia: Historicidade do Conhecimento e Construção da Aprendizagem 2003. RJ: Vozes, p. 50.

7 HORN, Geraldo B. Apresença da Filosofia no Curriculo do Ensino Médio Brasileiro: Uma Pespectiva Histórica. Petrópolis, RJ: Vozes, 2000, p. 20.

${ }^{8}$ Conceito usado por Adorno que visa denunciar a formação docilizadora.

${ }^{9}$ A organização e o plano de estudos proveniente da apropriação de São Tomais de Aquino da filosofia Aristóteles, que principiava a ordem por meio da construção de um sistema centralizador. Pedagogicamente ela se caracteriza pela repetição e pelo sentido livresco.

10 HORN, Geraldo B. Apresença da Filosofia no Curriculo do Ensino Médio Brasileiro: Uma Pespectiva Histórica. Petrópolis, RJ: Vozes, 2000, p. 28.

11 KOHAN, Walter Omar. O Ensino da Filosofia Frente à Educação como Formação. Petrópolis, RJ: Vozes, 2003, p. 47.

12 CABRERA, Julio. Diário de um Filósofo no Brasil. ljuí: Unijuí, 2010, p. 12.

13 CABRERA, Julio. Diário de um Filósofo no Brasil. ljuí: Unijuí, 2010, p. 14.

${ }^{14}$ ADORNO, Theodor W. Educação e Emancipação. São Paulo: Paz e Terra, 2012, p. 34.

${ }^{15}$ HOKHEIMER, Max. Eclipse da Razão. São Paulo: Unesp, 2015, p. 180.

16 HOKHEIMER, Max. Eclipse da Razão. São Paulo: Unesp, 2015, p. 183.

17 HOKHEIMER, Max. Eclipse da Razão. São Paulo: Unesp, 2015, p. 183.

18 ADORNO, Theodor W. Educação e Emancipação. São Paulo: Paz e Terra, 2012, p. 48.

\section{Correspondência}

Maria Clara Pereira Santos - Av. Sen. Salgado Filho, 3000, bairro, CEP: 59082270, Candelária, Rio Grande do Norte, Brasil.

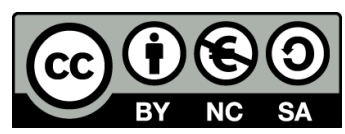

This work is licensed under a Creative Commons Attribution-NonCommercial 4.0 International (CC BY-NC 4.0) 